\title{
Correction to: Elevated ad libitum alcohol consumption following continuous theta burst stimulation to the left-dorsolateral prefrontal cortex is partially mediated by changes in craving
}

Adam M. McNeill ${ }^{1} \cdot$ Rebecca L. Monk ${ }^{2,3} \cdot$ Adam W. Qureshi $^{2,3} \cdot$ Stergios Makris $^{2} \cdot$ Valentina Cazzato $^{4} \cdot$ Derek Heim $^{2,3}$

Published online: 30 August 2021

(C) The Psychonomic Society, Inc. 2021

Correction to: Cognitive, Affective, \& Behavioral Neuroscience https://orcid.org/10.3758/s13415-021-00940-7

This article was updated to correct Valentina Cazzato's name and affiliation.

Publisher's note Springer Nature remains neutral with regard to jurisdictional claims in published maps and institutional affiliations.

The online version of the original article can be found at https://oi.org/ 10.3758/s13415-021-00940-7

Adam M. McNeill

mcneilla@outlook.com

1 School of Social Sciences, Birmingham City University, 4 Cardigan Street, Birmingham B4 7DB, UK

2 Department of Psychology, Edge Hill University, St Helens Road, Ormskirk L39 4QP, UK

3 Centre for Alcohol Research, Liverpool Health Partners, 1st Floor, IC3, Science Park, 131 Mount Pleasant, Liverpool L3 5TF, UK

4 School of Psychology, Liverpool John Moores University, Byrom Street, Liverpool L3 3AF, UK 